\title{
Does the information in the phase of low frequency LFP reflect the low frequency envelope of local spike rates?
}

\author{
Sohail Siadatnejad ${ }^{1 *}$, Stefano Panzeri ${ }^{2},{\text { Christoph } \text { Kayser }^{3} \text {, Nikos K Logothetis }}^{3,4}$, Marcelo A Montemurro \\ From Twentieth Annual Computational Neuroscience Meeting: CNS*2011 \\ Stockholm, Sweden. 23-28 July 2011
}

Recently, it has been shown that when the timing of spikes is measured relative to the phase of the cortical local field potentials (LFP), spikes can carry substantial more information about an external stimulus [1]. Experimental studies in sensory cortices of macaque have shown that the extra information obtained with such phase-of-firing codes above that in the firing rate alone ranges from $55 \%$ in primary visual cortex [1] to more than $100 \%$ in primary auditory cortex [2]. Here, we use a mathematical model that relates local spike trains and the resulting LFP, to explain the emergence of the phase-of-firing codes in cortex. The model is based on the one proposed in [3] and incorporates two types of integration over the spiking activity: i) a time convolution that results from the filtering properties of neural structures [4], which embeds history effects in LFP from past spiking activity, and ii) an integration step over the activity of neurons in the neighbourhood of the measuring electrode.

When the spikes recorded from macaque primary visual cortex were used to synthesize the LFP, the model could reproduce the phase-of-firing information found using the real LFP, as shown in Figure 1. This suggests that an important component of phase-of-firing
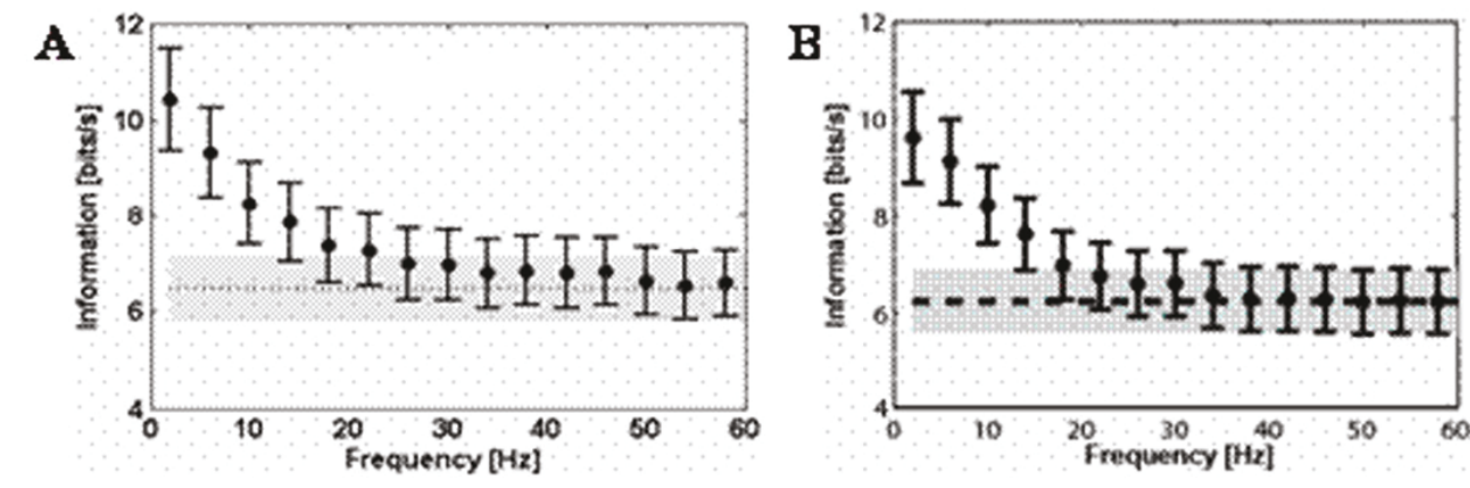

Figure 1 Comparison of the phase-of-firing information using synthetic and real LFP. The original data corresponds to LFP and spiking activity from 78 recordings channels in macaque V1, obtained while the animals were presented a movie [1]. $\mathbf{A}$. Information in the phase-of-firing code as a function of the LFP frequency band (black dots, with error bars indicating SEM over the dataset), and in the spike count (dashed line, with SEM indicated by grey area). In this panel, the LFP was simulated using real spikes with a mathematical model based on the one in [3]. B. As in A, however in this case both spikes and LFP correspond to real data [1].

\footnotetext{
* Correspondence: sohail.siadatnejad@postgrad.manchester.ac.uk

'Faculty of Life Sciences, University of Manchester, Manchester, M13 9PT, UK

Full list of author information is available at the end of the article
} 
information originates from the surrounding neural population and past spiking activity. The next question that arises is what is the relative contribution of the neuron population size and the length of the firing rate history embedded in the LFP. We are currently investigating this question by parametrically varying both the population size and time integration ranges in generating the synthetic LFP.

\section{Acknowledgements}

MAM and SP acknowledge support from the UK Engineering and Physical Sciences Research Council (EPSRC) grant EP/C010841/1 (COLAMN)

\section{Author details}

'Faculty of Life Sciences, University of Manchester, Manchester, M13 9PT, UK.

${ }^{2}$ Robotics, Brain and Cognitive Sciences Department, Italian Institute of

Technology, Genoa, 16163, Italy. ${ }^{3}$ Max Planck Institute for Biological

Cybernetics, Tübingen, 72076, Germany. ${ }^{4}$ Imaging Science and Biomedical

Engineering, University of Manchester, Manchester M13 9PT, UK.

Published: 18 July 2011

\section{References}

1. Montemurro MA, Rasch MJ, Murayama Y, Logothetis NK, Panzeri S: Phaseof-firing coding of natural visual stimuli in primary visual cortex. Curr Biol 2008, 18(5):375-80.

2. Kayser C, Montemurro MA, Logothetis NK, Panzeri S: Spike-phase coding boosts and stabilizes information carried by spatial and temporal spike patterns. Neuron 2009, 61(4):597-608.

3. Bédard C, Kröger H, Destexhe A: Does the 1/f Frequency Scaling of Brain Signals Reflect Self-Organized Critical States? Phys. Rev. Lett 2006, 97:118102.

4. Pettersen KH, Einevoll GT: Amplitude Variability and Extracellular LowPass Filtering of Neuronal Spikes. Biophys J 2008, 94(3):784-802.

doi:10.1186/1471-2202-12-S1-P227

Cite this article as: Siadatnejad et al:: Does the information in the phase of low frequency LFP reflect the low frequency envelope of local spike rates? BMC Neuroscience 2011 12(Suppl 1):P227.

\section{Submit your next manuscript to BioMed Central} and take full advantage of:

- Convenient online submission

- Thorough peer review

- No space constraints or color figure charges

- Immediate publication on acceptance

- Inclusion in PubMed, CAS, Scopus and Google Scholar

- Research which is freely available for redistribution

Submit your manuscript at www.biomedcentral.com/submit
C Biomed Central 